\title{
Mastering the Central Line Placement Techniques Through Effective Resident Training Environment
}

\author{
V.V. Protas
}

\begin{abstract}
Catheterization of the central vein is one of the fundamental procedures in anesthesiology. Mastering different methods of central venous access is an important part of resident training. At the initial stage residents should master the way of high medial access to the right internal jugular vein that is one of the simplest techniques with the lowest risk of complications for a patient. The operating room can be an optimal training environment where first independent puncture attempts are performed in a stable patient undergoing surgical intervention under general anesthesia. The next stage of training should involve access to other central veins as well performing the procedure in a conscious patient.
\end{abstract}

\section{Keywords}

central venous catheterization; practical skills

Ivano-Frankivsk National Medical University, Ivano-Frankivsk, Ukraine

Corresponding author: dr.vp@ukr.net

Catheterization of the central vein is a routine procedure in the practice of an anesthesiologist. Getting a central venous access is often crucial for a critical patient when haemodynamic monitoring / administration of medications through the central vein determines the outcome of treatment. Therefore, mastering the central line placement techniques is an important part of the resident training [1-4].

In practice, catheterization of the subclavian and internal jugular vein, rarely - femoral, with the inability to access the system of the upper vena cava is used more often.

Mastering of the central venous access is possible in the ICU ward or operating room. The ICU setting is more complicated due to the severity of the patients and specifics of their pathology, the lack of time, the impossibility of proper placement due to various causes and high-risk complications. All of the mentioned does not create the optimal environment for the initial learning of classic techniques. It should also be noted that for a resident, it's easier to perform on unconscious patients (with the pathology of the central nervous system, or those who receive analgesia \pm myoplegia). Finally, residents find it more difficult to concentrate on procedure, if others not involved in the procedure - are watching them.

Taking all this into account, operating room environment would be more favorable for training of this kind: a stable patient in conditions of general anesthesia, the lowest risk of catheterization complications and the simplest technique catheterization of the internal jugular vein through the high medial access. Therefore, mastering this technique should be the first stage of resident training.

Effective training on intraoperative catheterization of the internal jugular vein requires the followingf conditions:
1. No threat to the life of the patient / no need for emergency (shortage of time) catheterization of the central vein (bleeding, shock).

2. No significant hypovolemia, which leads to reduction in the diameter of the internal jugular vein and to additional difficulties with the puncture of the vein.

3. A possibility to change the patient's posture to the Trendelenburg position (without harm to the patient and worsening of the working conditions of the surgeon) in order to increase blood flow to the jugular vein.

4. Absence of vascular-platelet and coagulation hemostasis disorders.

5. "Favorable" anatomical features of the patient: relatively thin and long neck to facilitate identification of the larynx, trachea, carotid artery, sternocleidomastoid muscle.

At the first stage of training, the resident doctors learn indications and contraindications to the procedure, possible complications, specifics of preparation, necessary equipment, etc. Using visual materials such as educational films is also very helpful. Later the supervisor personally demonstrates the performance of the procedure, commenting on his/her actions and answering the questions.

After mastering the theoretical foundations, one can proceed to the practical part. At first, the resident doctor should try to perform less dangerous manipulation steps for a couple of times, namely conducting a catheter with the help of guidewire to the required depth, collecting blood from the 
catheter, cleansing it and fixing it to the skin. In the subsequent classes, it is advisable to let the resident make a central vein puncture and move conductor through a needle (according to Seldinger) under the control of supervisor. At the beginning we practice joint performance of procedure: the supervisor is ready to assist and guide the resident, if necessary, and constantly expresses his/her verbal support (extremely important for the beginners).

Access to the right internal jugular vein is simpler than to the left one, so it is advisable to first master the technique from the right side.

As a rule, 7-10 successful catheterization attempts, performed under the supervision, lay the foundation of the basic experience and give confidence to master the alternative techniques.

Since the ultrasound-guided catheterization of the central vein has been lately widely used in practical anesthesiology, it is necessary, if possible, to demonstrate this technique to the residents [5].

To sum it up, basic skills training in anesthesiology requires staging the resident training process and creating appropriate conditions that increase the likelihood of successful attempts and self-esteem of the residents.

\section{Conclusions}

1. Creating a favourable resident training environment is essential to effectively master the central line placement techniques, taking into account patient's well-being and general conditions under which the procedure is performed.

2. High medial access to the right inner jugular vein is the easiest way of mastering central vein catheterization.

\section{References}

[1] Chan A, Singh S, Dubrowski A, Pratt DD, Zalunardo N, Nair P, et al. Part versus whole: a randomized trial of central venous catheterization education. Adv Health Sci Educ Theory Pract [Internet]. 2015 Oct [cited 2015 Feb 1]; 20(4):1061-71. DOI: https: / / doi.org/10.1007/ s10459-015-9586-0

[2] Miranda JA, Trick WE, Evans AT, Charles-Damte M, Reilly BM, Clarke P. Firm-based trial to improve central venous catheter insertion practices. J Hosp Med [Internet]. 2007 May;2(3):135-42. DOI: https : / / doi . org/10. $1002 / \mathrm{jhm} .168$

[3] Grover S, Currier PF, Elinoff JM, Mouchantaf KJ, Katz JT, McMahon GT. Development of a test to evaluate residents' knowledge of medical procedures. J Hosp Med [Internet]. 2009 Sept;4(7):430-2. DOI: https : / / doi . org/10. $1002 / \mathrm{jhm} .507$

[4] Rodriguez-Paz JM, Kennedy M, Salas E, Wu AW, Sexton JB, Hunt EA, et al. Beyond "see one, do one, teach one": Toward a different training paradigm. Qual Saf Health Care[Internet]. 2009 Feb [cited 2009 Feb 09];18(1):63-8.DOI: https : / / doi .org/10.1136/ qshc. 2007.023903

[5] Bayci AW, Mangla J, Jenkins CS, Ivascu FA, Robbins JM. Novel educational module for subclavian central venous catheter insertion using real-time ultrasound guidance. J Surg Educ [Internet]. 2015 Nov-Dec [cited 2015 Oct 15];72(6):1217-23 DOI: https : / / doi . org/10 . $1016 / j \cdot j$ jurg.2015.07.010

Received: 28 Mar 2018

Revised: 16 Apr 2018

Accepted: 28 May 2017 